\title{
Computer Operating System Problem
}

National Cancer Institute

\section{Source}

National Cancer Institute. Computer Operating System Problem. NCI Thesaurus. Code C63270.

Problem associated with software, firmware, and/or hardware elements that control the execution of computer programs and provides such services as computer resource allocation, job control, input/output control, and file management in a computer system. 